\title{
A Course Based Approach to Recognizing Student EFFORTS IN ENGINEERING DESIGN COMPETITIONS
}

\author{
Patrick Dumond \\ Department of Mechanical Engineering, University of Ottawa \\ pdumond@uottawa.ca
}

\begin{abstract}
Recently, the University of Ottawa has sought to increase experiential learning opportunities for its engineering students. A great deal of effort has been made to remove barriers and increase resources for students participating in large-scale international engineering design competitions. However, so far students involved have participated in these extracurricular activities purely out of interest and to gain experience.

In this paper, we seek to recognize this immense effort made by students by developing a course in which students can receive credits for working on these projects. The course was split into two sessions per week involving three hours of lecturing, practical learning activities and group meetings with full guidance from the instructor and three hours of laboratory time for students to work on their project.

A few key aspects of the course were found to highly benefit the teams that had participating members in the course. A technical skill development project requiring each student to develop a new skill considered useful by their teams, proved to be the course highlight. Inter-team collaboration developed and continued after the course ended. Other aspects, while beneficial, would require improvement in future offerings the course. Extensive design report writing and presentations in the course solidified participating students' abilities in these aspects, which was made evidently clear during these portions of each competition, but drew extensive complaints from students. Customized quizzes related to the specific competition rules for each team, given early on, gave poor results but helped strengthen rule compliance compared to previous years. Finally, improved team organization and a significant increase in team performance at competition was achieved by all teams who had students participating in the course, demonstrating the course's success.
\end{abstract}

Keywords: Engineering Design Course, Engineering Competitions, Experiential Learning, Project Based Learning.

\section{INTRODUCTION}

Flipped classrooms, problem-based learning and project-based learning have become popular alternatives to traditional lecture based methods when teaching engineering design [1], [9], [10], [13]-[15]. While each method presents advantages and disadvantages, no universally accepted winner has emerged as demonstrating significantly better results in engineering design skills of emerging graduates. Ongoing research is trying to pinpoint exact techniques which enhance student comprehension and ability related to various design skills [8]. Moreover, the Canadian Engineering Accreditation Board continues to emphasize engineering design throughout engineering curricula [5], which has increased the effort that engineering faculties across Canada have placed on creating meaningful design experiences for their students throughout their programs.

Experiential learning has become one such popular technique in engineering design, due to the fact that it allows students to work on real projects, hopefully better preparing them for the real world [4], [8], [16]. While, little research has actually proven the effectiveness of this approach, personal experience has shown that experiential learning opportunities certainly help in getting students interested in engineering design and motivating them to work harder and spend more time learning outside the classroom (life-long learning). As many other universities have done recently, the Faculty of Engineering at the University of Ottawa has been hard at work developing and promoting such experiential opportunities.

One avenue the University of Ottawa has pursued vigorously is team-based international engineering design competitions. These provide preexisting structures in which students can learn and practise engineering design skills by applying them to real problems within real time and budgetary constraints and which also provides measurable results for peer and self-assessment. Furthermore, these competitions enable peer interaction within an institution and also external to it, which broadens these students' perspective on engineering as a whole. Over the last seven years, the University has 
worked hard at removing barriers for students seeking to join or create competition teams, obtaining funding for the projects, developing student fabrication facilities and providing work spaces. As it currently stands, the University of Ottawa provides significant support (in all aspects) to seven extracurricular teams participating in major international engineering competitions on a yearly basis. The university also offers support to many smaller groups participating in smaller engineering competitions on an ad hoc basis.

In most cases, students participating in these engineering design competitions do so out of pure interest, seeking to gain nothing but experience from the project. In all cases, extracurricular time investment in any given project is enormous and knowledge and skills gained throughout the process is obvious. The University of Ottawa has sought to recognize these students by providing course credits for their effort. One method, which has been used by other institutions to enable this recognition is through senior level capstone projects [12], a method which has also been implemented in the Department of Mechanical Engineering at the University of Ottawa [7]. Unfortunately, the current single term structure provided does not allow students to follow through with the fabrication of their designs.

Therefore, the method chosen for providing specific credits for these extensive efforts involved the creation of a final-year engineering technical elective course called "Design Studio", which has allowed students to work on their project during lab hours, while providing them with active guidance and formal training in design best practices specific to the competitions during lecture hours. Course registration was limited to those who had been active team members previously or who had shown keen interest in one of the team projects and who was approved as a recruit for one of the teams by the team captain. The first iteration of the course occurred in the winter of 2016. As a trial, the course was run as part of the Mechanical Engineering program and included four competition projects: SAE Supermileage, Shell Eco-marathon, Baja SAE and Formula North. Before the term even began, students expressed great interest in the concept and no difficulties were had in finding valid candidates for registration. A total of fifteen students participated in the first offering of the course split almost evenly across the different competition projects.

\section{COURSE STRUCTURE}

The primary purpose of the course was to recognize the efforts of senior students working on large scale engineering design competition projects by providing them with course credits. However, since course credits were being offered, an opportunity to build a solid curriculum around the project also presented itself, which could not only help solve common complaints, but which could also help improve various aspects of these projects, including the knowledge and skills of the students themselves.

\subsection{Common Complaints}

As faculty advisor to a number of engineering competition teams over the years, a fair share of complaints from project members relating to various aspects of the projects have come up. Some of the more obvious complaints include limited financial, equipment, facility and technical resources. Other less obvious complaints include difficulty in finding common meeting/work times for all members due to hectic course loads and varying course schedules or lack of real time/project management training and practice. Moreover, many keen students complained that it was difficult to schedule and complete important machining training which would allow them to fabricate project components on time and within budget.

\subsection{Resource Improvement}

A key aspect which aided in the delivery of "Design Studio" and which predated the development of the course itself was the significant improvement in financial, equipment and facility resources provided to the competition teams through initiatives made possible by an NSERC Chair in Design Engineering. Without the improvement of these resources, efficient and effective delivery of such an experiential course would not be possible. These initiatives included a larger pool of money available to competition teams each season to be used in the purchase of materials or the machining of components for their projects, as well as the significant improvement of the student design and prototyping space (workshop), which included the purchase of new tooling and fabrication equipment.

\subsection{Curriculum}

The course curriculum was created in order to help address some of the most common complaints heard from students. The easiest inclusion was to create a laboratory time slot for the course, which provided the students taking the course a three hours common time slot per week to work on the project together. The laboratory was made mandatory, but location of work was flexible (workshop, makerspace, class, etc.) based on preapproval by the instructor and teammates.

Since, students were receiving course credits, it also seemed important to include three hours per week of lecture time which could be used for various reasons, 
including actual lecturing on topics related to the projects, providing guidance and doing team meetings in the presence of the instructor. The first half of the term saw more time spent on traditional lecturing mixed with activities designed to practise what was learnt. Lecture topics included:

- Introduction/review of the design process [2];

- Review of project management, planning (budget, schedule, and resources), execution (monitoring and control) and closure [3];

- Review of basic design for $X$ concepts, evaluating and analyzing designs, as well as improving designs for manufacture, assembly, reliability and reparability [11];

- Review of numerical tools for design (FEA, CFD, CAD/CAM, topology optimization, mathematical and instrumentation software) and their proper use and limitations in various design situations;

- Review of salesmanship, marketing, public relations and fundraising techniques for large projects [6];

- Competition day strategy.

In all cases, emphasis was placed on providing students with practical tools that could be used directly on their projects, rather than traditional theory. In some cases, specific references were chosen for these lectures which also emphasized the use of practical tools. These references are included in the list above. During lecture hours, students were given the opportunity to apply the practical tools learned during the lecture directly to their given project. The instructor ensured that students were working on applying these tools to their projects correctly by sitting in on these group activities with each team and ensuring their successful follow through.

Lectures were interspersed with individual progress presentations by the students which not only allowed the instructor to follow the individual progress of each student, but also allowed their classmates to understand and comment on their progress while providing important and insightful feedback as well.

\subsection{Marks}

Marks are commonly regarded as an effective motivator for students. Therefore, marks given throughout the course were intended to help motivate students to work more seriously on their projects sooner and to increase the quality of their results. The grading scheme for the first iteration of the course is shown in Table 1.

In order to ensure improved designs early on, minimize wasted efforts and increase the odds of competition success, customized extended quizzes were given in the second week of the course. These quizzes were intended to test the knowledge and understanding of students regarding the specific competition rules.

Table 1: Grading scheme.

\begin{tabular}{|l|c|}
\hline Evaluation & Grade Percentage \\
\hline Quiz & 5 \\
\hline Shop training & 5 \\
\hline Participation & 5 \\
\hline Health, safety and cleanup & 5 \\
\hline Log book & 10 \\
\hline Group design project & 50 \\
\hline Skill development project & 20 \\
\hline
\end{tabular}

Since prototyping and fabrication related to the actual competition projects were intended to be an integral part of the course at the outset, it was important to ensure that all students in the course had the basic fabrication skills required to work on their projects. Shop training occurred at the beginning of the first few weeks of labs, where necessary, and included:

- Basic machine shop procedures and safety;

- Hand tools, band saw and drill press;

- Sheet metal working;

- Mill and lathe;

- Welding;

- 3D printing and laser cutting

- Basic electronics and programming.

Given that a number of students were active team members already, many had some of the training listed above. However, all the students in the course benefitted from some basic training in the first two weeks and the marks for this portion of their grade were based on their participation and effort in these sessions. Similarly, marks for participation were given for student participation and effort throughout the rest of the course activities and laboratory sessions. Additionally, because a large proportion of the weekly laboratory sessions would be spent in the workshop working on the fabrication and assembly of their projects, a great deal of emphasis was placed on health, safety and cleanup procedures. In order to ensure these procedures were being followed and to make it easier in providing marks, each week two or three students were identified as the health, safety and cleanup procedure leads. Their responsibility was to ensure compliance by all students. Students were motivated in following the directions of weekly leads, as their turn as leads would also come up multiple times over the term.

From the outset, the course was run as an engineering design firm working on large scale projects. To this effect, competition teams would continue to run external to the 
course and the course would therefore need to contend with students not taking the course, but also working on the projects. For this reason, students in the course would not be working on the projects as a whole, but rather on specific sub-projects dedicated to the course. Students were split into groups of two (three in the case of an odd number of students) and each group needed to propose a design-fabricate project complex enough to last the duration of the term as judged by the instructor based on experience. In a few cases, multiple simpler projects were proposed and accepted as valid alternatives. Project proposals were required by week two of the course in order to ensure a quick start. Weekly in class meetings were required between group members and also between team members taking the course. Weekly team meetings external to the course were also highly recommended so as to include students who were not taking the course in the progress of the projects.

In order to ensure proper documentation of design ideas, analysis and progress, as well as to reduce confusion among these various levels of student interactions, a log book was required and verified throughout the term for consistent and organized use. The use of a $\log$ book while working on engineering design projects was considered as a good habit to build during the development of the course and was therefore emphasized throughout the term. The group design projects were marked in a number of ways as shown in Table 2.

Table 2: Group design project deliverables.

\begin{tabular}{|l|l|}
\hline Week & Deliverables \\
\hline 2 & Group formation and project proposals \\
\hline 3 & Project plan and responsibilities \\
\hline 5 & Team succession plan \\
\hline $6-9$ & Midterm progress report and presentation \\
\hline End of term & Final report and presentation \\
\hline End of term & Peer evaluation \\
\hline
\end{tabular}

Team succession planning seemed to be an important inclusion for the course, as competition teams have struggled in the past with recruiting and maintaining a constant flow of multiyear students in order to keep teams sustainable and successful. Midterm progress presentations were done individually and gave weekly updates on team progress during the second half of the term.

The most unique aspect of the course was the inclusion of a skills development project. Since each competition has distinct needs and goals, customized learning was sought. This was achieved by introducing a self-learning feature to the course. Students were tasked with developing a new specialty skill that would be useful in ensuring their team's success in the competition. The proposed technical skill which would be developed in the course had to be a skill never before attempted by the student or one which was an advanced addition to some basic skill already acquired by the student. In either case, the technical skill had to be useful to their team. Examples include advanced machining and welding, advanced electronics and programing or the use of advanced numerical software. Since the purpose of any course is to learn, students were also tasked with reporting on their new skill and to provide tips and tricks to save their classmates time in the event they wanted to learn the skill in the future. A breakdown of the marks provided for the technical skill development project is shown in Table 3.

Table 3: Technical skill development project deliverables.

\begin{tabular}{|l|l|}
\hline Week & Deliverables \\
\hline 3 & Specialty skill and project proposal \\
\hline 12 & Skill presentation and report \\
\hline
\end{tabular}

Overall, communication skills, both written and oral, represented a large portion of the marks given in the course. This was done purposefully as experience has shown that left to their own devices, competition teams typically spend much more time on engineering design, analysis, fabrication and assembly rather than practising and delivering on the communication aspects of the competitions.

\section{DISCUSSION}

By many accounts, this first iteration of the "Design Studio" course was a success. However, like any new endeavour, many improvements could be made to make the course even better.

\subsection{Competition Rules Quiz}

While the goal of offering customized quizzes early in the course based on the rules specific to each competition was to ensure that all students in the course understood the design constraints under which they were working, some students complained about the length of the rules and their inability to memorize the details. In most cases, the results of these quizzes were poor. Two factors contributed to poor results. The first involved the varying length of the rules depending on which competition students were participating in (i.e. the Formula North competition requires the compliance with a significantly larger number of rules compared to the SAE Supermileage competition and therefore Supermileage team members performed better on their quiz on average than their Formula counterparts). The second reason was that some students in the course had never participated in their respective competitions prior to the course being offered. As anyone 
who has gone to competition knows, it is much easier to know and understand the rules of a competition once you have gone through technical inspection with your competition team at least once, than to memorize the rules from reading them. That being said, as the actual competition dates approached, students expressed their appreciation for such a quiz early in the term as it forced them early on to read through all the rules and know the constraints that would prevent compliance issues as time was running out. Nonetheless, the results were disappointing and for the next offering of the course, a second quiz would be beneficial if given closer to the end of the term in order to measure how the students have learned and understood the rules as they work on their project, but also to remind them of compliance related issues as they are finalizing their components and preparing to integrate them in their assemblies.

\subsection{Succession Planning}

Succession planning is such a vital component in maintaining successful large engineering competition teams year after year. However, it is usually placed on the back burner of most teams who argue that they are too busy with doing engineering design, fabrication and assembly. Including succession planning in "Design Studio" and making it worth marks seemed like a clever way of ensuring it occurred. Although the succession plans provided by the groups as part of their design project deliverables were well prepared and received, they suffered from a severe lack of follow through by all teams. It is recommended that such a succession plan deliverable occur near the very beginning of the term and that further marks are given at the end of the term for the students' abilities to actually follow through with the plan over the term.

\subsection{Midterm Progress Presentations}

Midterm progress presentations carried on too close to the final presentations and started to become redundant. Beginning the progress presentations sooner in the term interspersed with lecture topics would help improve classmate interest in the presentations and also ensure that progress on the projects was occurring sooner.

\subsection{Technical Skill Development Project}

By far the most enjoyed feature of the course by both the students and the instructor was the technical skill development project. Self-learning was motivated by the fact that students were developing new skills chosen by themselves and which would be useful for a project they were already seriously involved in. Many students acknowledge that without the incentive of marks and the time allocated in the course, they would not have otherwise been able to develop such skills (or have been able to improve such skills to a useful degree). Moreover, students were excited to report on and present their newly learned skills while demonstrating the results of these skills with the practice project they had worked on. A number of students were able to take away tips and tricks learned the hard way from their classmates while learning the basics of these skills themselves.

A further interesting outcome of the course which only expressed itself well after the course was over was the training these students provided their teammates related to these new skills and the confidence these students demonstrated in acting as instructors. In fact, many students that were not partisan to the course also benefited from the skills development which occurred as part of the course. This phenomenon has continued to propagate through the ranks of the teams to this day.

\subsection{Global Outcome}

The course proved to be a great success in great part due to the keen interest of students already participating in these engineering competitions as an extracurricular activity. Participation and efforts in the course were above par when compared to typical design courses. While not all aspects of the course were appreciated by all students, the fundamental structure of the course seemed to work well. Common positive feedback provided by the students included: "provides incentive to work harder on the project sooner", "gave great guidance on design and fabrication issues often overlooked by the teams", "lectures offered good insight and experience on competition strategy and requirements", "enjoyed the hands-on perspective of the course" and "finally gave an opportunity to apply theory seen in other classes to a real project". Negative feedback for the first iteration of the course included: “assignments and reports didn't always reflect what was needed for competition and took away time from building", "projects were too hard to complete successfully in three months" and "too much report writing", although a significant improvement in the communication aspects of each competition was observed.

One of the biggest beneficial outcomes of the course was the interaction that occurred between competition teams. Prior to the existence of the course, each team worked rather independently of each other. Moreover, each team came into the course with specialized knowledge related to their own projects. During the course, teams were able to share this knowledge and help each other out. This comradery between teams has since transcended the course and has become omnipresent at the University of Ottawa. This in itself has provided a large boost to all existing and new competition teams. 
As for the competitions themselves following the course in the summer of 2016, the results speak for themselves. At the SAE Supermileage competition, the team was able to jump in the standings from their previous year's $9^{\text {th }}$ place performance to an outstanding $5^{\text {th }}$ place while doubling their fuel economy score. At the Shell Eco-marathon, the team was able to pass technical inspection and complete a valid run for the first time ever. They placed $16^{\text {th }}$ overall with a great fuel economy score. At the Baja SAE competition, the team was able to pass technical inspection and complete all dynamic events for the first time ever. They placed $70^{\text {th }}$ overall. Although the Formula team was unable to complete the technical inspection at the Formula North competition, they were able to show up to the event with a fully functional vehicle. In fact, 2016 represented the first year a successful attempt was made at creating a Formula car at the University of Ottawa. It is strongly believed by all those involved that without the course, the Formula project would never have come to fruition and that the team may not have continued to exist moving forward. Photos of the teams and their resulting completed projects are provided in appendix A.

As a final note, based on the experience gained in this first iteration of "Design Studio", for best results it is important that the instructor has good experience in working on and attending engineering competitions. From the author's perspective, it is often easy to overlook what is important without having attended one of these competitions and the instructor is better able to provide specific insight to the teams in order to increase their chances of success at competition.

\section{CONCLUSIONS}

While "Design Studio" represents a new approach to recognizing student efforts in engineering design competitions, the course based method described has also proven to be successful in encouraging better results than when students are left to their own devices. Many aspects of the course have not only motivated students to work on their projects sooner, but also improved the quality of their work. In particular, the skill development project was very much appreciated by the students and provided a means to promote life-long learning while adding useful skills to each team's arsenal. An unexpected beneficial outcome was that collaboration between the teams was developed as a result of the course, which continues to transcend the teams long after the end of the course. Other aspects of the course, such as the competition rules quizzes, succession planning and midterm progress reports still require improvement in order to optimize their value in future offerings. Finally, the lectures and guidance provided to the students based on practical tools and insight worked well in the context of this course and the particular competition projects involved.

\section{Acknowledgements}

The author would like to acknowledge the generous support provided by the Natural Sciences and Engineering Research Council of Canada, as well as Hanan Anis, uOttawa's Chair in Design Engineering. The author would also like to thank Laura Haya for her help in the preliminary development of the course.

\section{References}

[1] J. L. Bishop and M. A. Verleger, "The flipped classroom: A survey of the research," in ASEE National Conference Proceedings, Atlanta, GA, 2013, vol. 30, pp. 1-18.

[2] F. P. Brooks Jr, The Design of Design: Essays from a Computer Scientist. Pearson Education, 2010.

[3] D. Burstein and F. Stasiowski, Project management for the design professional: a handbook for architects, engineers, and interior designers. Whitney Library of Design, 1991.

[4] R. Carrick, A. Czekanski, and M. R. Ha, "Building a More Complete Design Experience: Philosophies and Reflections from a Second Year Mechanical Engineering Design Project Course," Proc. Can. Eng. Educ. Assoc., Jun. 2016.

[5] CEAB, "2016 Accreditation Criteria and Procedures," Engineers Canada, 2016.

[6] D. G. Cooper, Architectural and engineering salesmanship. Wiley, 1978.

[7] P. Dumond and E. Lanteigne, "From Mechanical Engineering Capstone Design to Design Implementation," Proc. Can. Eng. Educ. Assoc., Jun. 2016.

[8] C. L. Dym, A. M. Agogino, O. Eris, D. D. Frey, and L. J. Leifer, "Engineering Design Thinking, Teaching, and Learning," J. Eng. Educ., vol. 94, no. 1, pp. 103-120, Jan. 2005.

[9] M. Frank, I. Lavy, and D. Elata, "Implementing the Project-Based Learning Approach in an Academic Engineering Course," Int. J. Technol. Des. Educ., vol. 13, no. 3, pp. 273-288, Oct. 2003.

[10] L. Helle, P. Tynjälä, and E. Olkinuora, "Project-Based Learning in Post-Secondary Education - Theory, Practice and Rubber Sling Shots," High. Educ., vol. 51, no. 2, pp. 287-314, Mar. 2006.

[11] G. Q. Huang, Ed., Design for X: Concurrent engineering imperatives. Springer Science \& Business Media, 1996. 
[12] S. Khorbotly and K. Al-Olimat, "Engineering studentdesign competition teams: Capstone or extracurricular?," in 2010 IEEE Frontiers in Education Conference (FIE), 2010 .

[13] M. Lehmann, P. Christensen, X. Du, and M. Thrane, "Problem-oriented and project-based learning (POPBL) as an innovative learning strategy for sustainable development in engineering education," Eur. J. Eng. Educ., vol. 33, no. 3, pp. 283-295, Jun. 2008.

[14] J. E. Mills, D. F. Treagust, and others, "Engineering education-Is problem-based or project-based learning the answer," Australas. J. Eng. Educ., vol. 3, no. 2, pp. 2-16, 2003.

[15] K. A. Smith, S. D. Sheppard, D. W. Johnson, and R. T. Johnson, "Pedagogies of Engagement: Classroom-Based Practices," J. Eng. Educ., vol. 94, no. 1, pp. 87-101, Jan. 2005.

[16] W. Stiver, "First Year Engineering Design - Guelph's Teddy Bear Wheel Chair Experience," Proc. Can. Eng. Educ. Assoc., Aug. 2015.

\section{APPENDIX A: COMPLETED PROJECTS}

All four projects involved in the trial run of "Design Studio" came to fruition. The final results of these projects and their teams can be seen in Fig. 1-4.

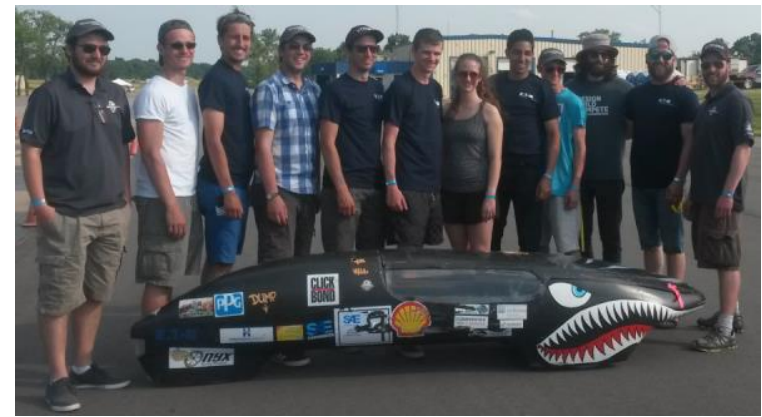

Fig. 1. SAE Supermileage.

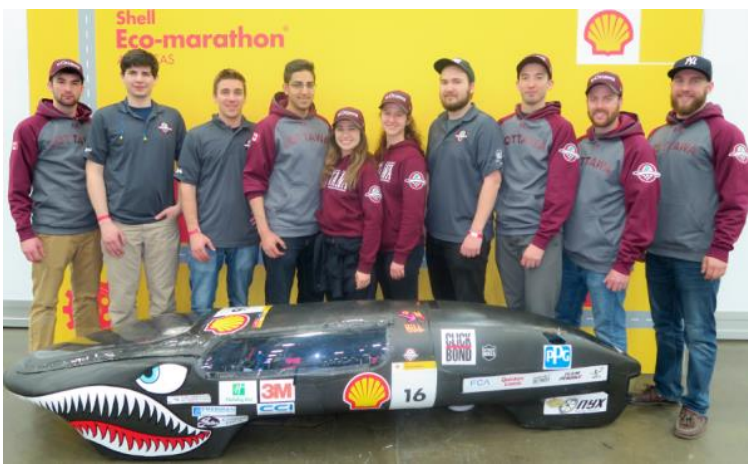

Fig. 2. Shell Eco-marathon.

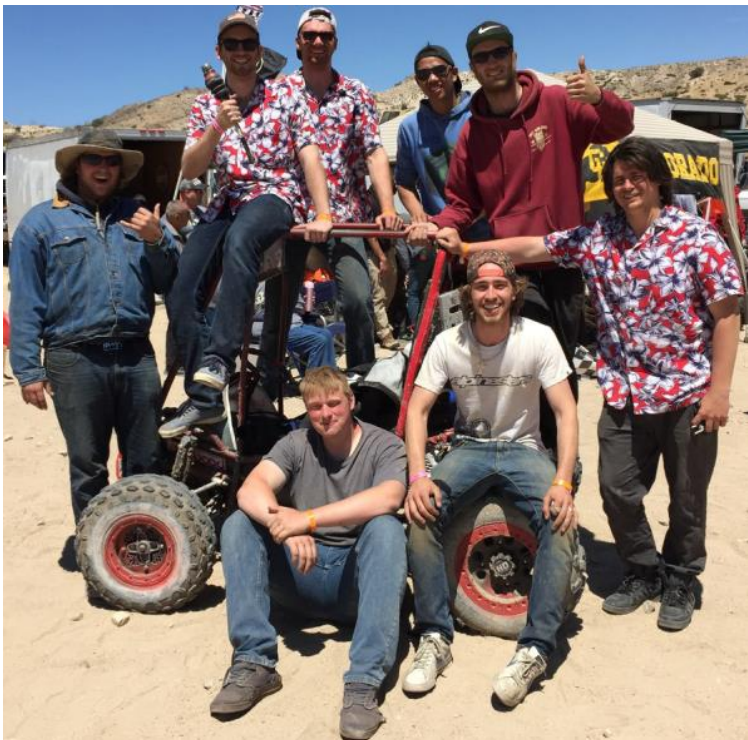

Fig. 3. Baja SAE.

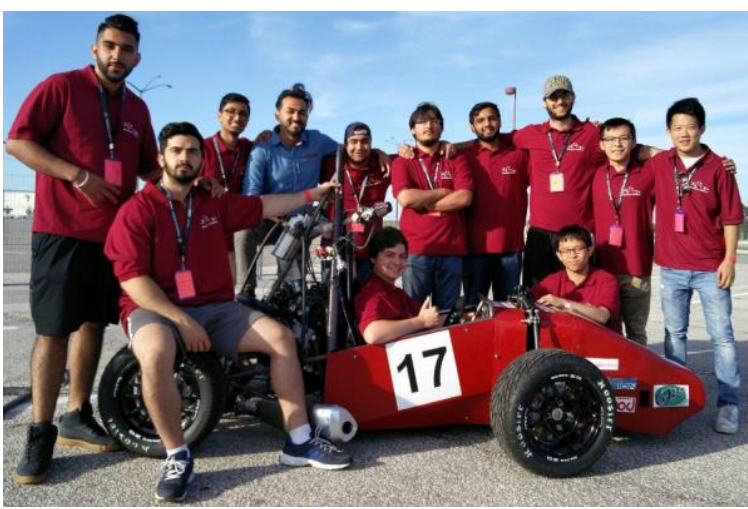

Fig. 4. Formula North. 